\title{
Assessment of thermally comfortable urban spaces in Amsterdam during hot summer days
}

\author{
Lisette Klok $^{1}$ - Niek Rood ${ }^{1}$ • Jeroen Kluck ${ }^{1}$ - Laura Kleerekoper ${ }^{1}$ \\ Received: 31 October 2017 / Revised: 29 June 2018 / Accepted: 30 October 2018 / Published online: 26 November 2018 \\ (C) The Author(s) 2018
}

\begin{abstract}
Since it is insufficiently clear to urban planners in the Netherlands to what extent design measures can reduce heat stress and which urban spaces are most comfortable, this study evaluates the impact of shading, urban water, and urban green on the thermal comfort of urban spaces during hot summer afternoons. The methods used include field surveys, meteorological measurements, and assessment of the PET (physiological equivalent temperature). In total, 21 locations in Amsterdam (shaded and sunny locations in parks, streets, squares, and near water bodies) were investigated. Measurements show a reduction in PET of 12 to $22{ }^{\circ} \mathrm{C}$ in spaces shaded by trees and buildings compared to sunlit areas, while water bodies and grass reduce the PET up to $4{ }^{\circ} \mathrm{C}$ maximum compared to impervious areas. Differences in air temperature between the locations are generally small and it is concluded that shading, water and grass reduce the air temperature by roughly $1{ }^{\circ} \mathrm{C}$. The surveys $(n=1928)$ indicate that especially shaded areas are perceived cooler and more comfortable than sunlit locations, whereas urban spaces near water or green spaces (grass) were not perceived as cooler or thermally more comfortable. The results of this study highlight the importance of shading in urban design to reduce heat stress. The paper also discusses the differences between meteorological observations and field surveys for planning and designing cool and comfortable urban spaces. Meteorological measurements provide measurable quantities which are especially useful for setting or meeting target values or guidelines in reducing urban heat in practice.
\end{abstract}

Keywords Thermal experience $\cdot$ Urban heat $\cdot$ Climate adaptation $\cdot$ PET $\cdot$ Outdoor thermal comfort $\cdot$ Urban planning

\section{Introduction}

In the next decades, urban planners and managers will increasingly need to address urban heat problems because of rising temperatures, more frequent and more extreme heat events, and the urban heat island effect (EEA 2016; IPCC 2014). Also for the Netherlands, heat stress in cities is expected to become an important issue (Molenaar et al. 2015; Steeneveld et al. 2011). However, several urban designers and planners in the Netherlands have indicated that they are struggling with this issue, since it is insufficiently clear to what extent urban design measures can reduce heat stress in Dutch urban areas,

Lisette Klok

e.j.klok@hva.nl

1 University of Applied Sciences Amsterdam, Weesperzijde 190, 1097 DZ Amsterdam, Netherlands and which outdoor urban environments are most comfortable during hot days.

To contribute to this discussion and to be able to advise urban designers and planners which cool and comfortable urban design measures they can take to adapt cities to urban heat, we assessed the thermal conditions of urban spaces. Detailed thermal assessments of outdoor urban spaces normally imply fieldwork studies in which micrometeorological investigations are combined with questionnaire surveys to evaluate the thermal effect in terms of air temperature, thermal comfort, and thermal perception (Lenzholzer et al. 2016).

Many thermal assessments of outdoor urban spaces and urban designs have been carried out in the recent past, especially in countries other than the Netherlands (e.g. Lindberg et al. 2016; Middel et al. 2016; Yahia and Johansson 2013; Thorsson et al. 2004). These studies might therefore not be applicable to the Dutch urban situation or the Dutch climate. Thermal assessments that have been carried out in Dutch urban spaces (e.g. Van 
Hove et al. 2015; Taleghani et al. 2015; Theeuwes et al. 2013) often focus on the physical thermal conditions only and exclude how people experience and value the thermal conditions. Actually, it was Lenzholzer (e.g. Lenzholzer and Koh 2010; Lenzholzer 2010) and Klemm (e.g. Klemm et al. 2015a, 2015b) who started to assess the thermal situations of Dutch urban spaces using a combination of micrometeorological measurements and interview surveys to evaluate the thermal experience. However, in their studies often only one type of urban space was assessed (squares or green spaces respectively). A study in which the microclimatic effects and thermal experience of multiple types of urban spaces, such as green and shaded areas and locations near water bodies, are compared to each other has not yet been carried out in Netherlands.

The main aim of this study is therefore to assess the thermal conditions of different urban spaces in Amsterdam and to identify which urban spaces are experienced and measured as most comfortable during hot summer days. We combined micrometeorological measurements from mobile weather stations with an extensive questionnaire survey to assess the thermal conditions of three types of urban spaces: impervious urban spaces, green urban spaces and urban spaces close to water bodies. All locations could be either sunlit or shaded by trees or buildings. The fieldwork was carried out between noon and late afternoon during 12 hot days in 2015 and 2016.

This study was accomplished within the framework of a Dutch applied research project 'Urban climate resilience - Turning climate adaptation into practice', which was concluded in 2016. The project aimed to support urban professionals and closely cooperate with urban professionals. The professionals in this project were especially interested in understanding which spaces in cities remain cool and comfortable during hot days in order to take this into account in their planning strategies and designs. They particularly wanted to know which urban spaces can generate substantial cooling. In the second year of the project, the professionals were especially interested in the cooling effect of water bodies in cities. Therefore, the analyses carried out in 2016 focused on the thermal effect of urban water bodies only.

In addition to assessing the thermal situation of different urban spaces in Amsterdam, we evaluate the added value of using questionnaire surveys in this paper. Are the micrometeorological measurements consistent or inconsistent with the results of the surveys, do they provide the same insight, do they contradict or complement each other? Do the results from the surveys add relevant information to the measurements in advising urban planners how to design thermally comfortable spaces? These questions will be touched on in the 'Discussion' section.

\section{Materials and methods}

\section{Measurement locations}

The urban spaces of which the thermal conditions were assessed are all located in Amsterdam. Amsterdam is the capital and the most populous city of the Netherlands. The number of inhabitants is nearly 850,000 (CBS 2017). The climate of Amsterdam is a temperate marine climate (Köppen climate classification $\mathrm{Cfb}$ ) and summers are normally moderately cool.

Nearly all measurement sites are located in the centre of Amsterdam (Fig. 1). They were selected because they are well-known and well-visited spaces. Well-visited locations are useful to collect a considerable number of surveys. The reason to select also well-known spaces is to enable the dissemination of the results to urban professionals, which is easier if they know the spaces and recognise the characteristics.

We assessed the thermal conditions of three types of urban spaces: (1) grey locations - impervious areas such as streets and squares, (2) green locations - green spaces such as parks existing of grass, shrubs and trees, and (3) blue locationsurban areas close to water bodies such as canals, rivers, ponds and fountains. Each location was either sunlit or in the shade of trees or buildings. On the basis of visual observations, we determined if a location was in the sun or in the shade. Locations were sunlit or shaded during the total measurement period. The measurement locations at the blue locations were always at the downwind direction of the water body and within a distance of $8 \mathrm{~m}$ from the water body. In total, 13 impervious urban spaces, 2 green urban spaces and 6 spaces near urban water bodies were assessed.

Table 1 gives an overview of the measured sites in Amsterdam, including the measurement date and period, the location type, the situation: sunlit or shaded, a description of the site and the Local Climate Zone (Stewart and Oke 2012) that we identified for each site. We always conducted measurements and surveys at two different locations at the same time and compared the thermal situations between the two sites to evaluate the thermal effects of green, water, and shading. The thermal effect was assessed by considering the differences in the average air temperature and physiological equivalent temperature (PET) over the entire measurement period, which is mostly from noon until the late afternoon, and the difference in the thermal experience of the respondents.

During some days in the first measurement year 2015, we moved the weather station each hour between a sunlit and a shaded location (see Table 1). By doing so, we could in addition assess the thermal difference between a sunlit and a shaded area for one type of location, apart from the thermal difference between two types of locations. For example, from the measurements at the locations Leidseplein (impervious 


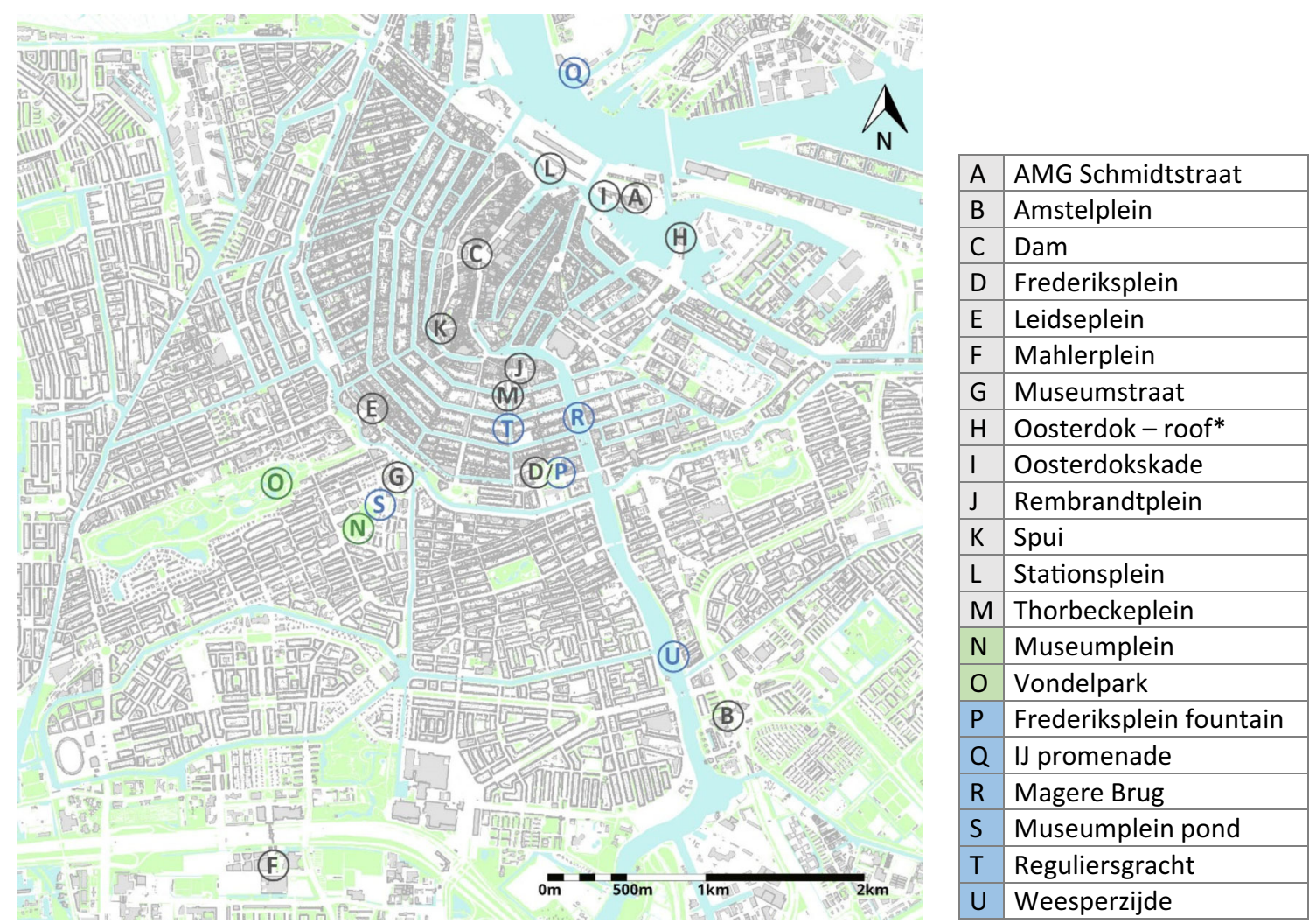

Fig. 1 Map of the measurement sites. The colour indicates the type of location: grey are impervious urban spaces, green are parks with grass, shrubs and trees, and blue are locations near urban water. The locations are numbered in alphabetical order. *Data measured at Oosterdok are not used in this paper

Table 1 Date of measurements, maximum air temperature measured at Schiphol airport $\left(T_{\mathrm{a}, \max }\right)$, name and type of location, situation with respect to sun or shade and description of the measured urban spaces, including tree species and dimensions of the water bodies and the Local Climate Zone (Stewart and Oke 2012). The colour indicates the type of location: grey are impervious urban spaces, green are parks with grass or shrubs and blue are spaces near urban water. It is indicated if measurements were done in the sun (yellow), in the shade of trees (green) or in the shade of buildings (red). Also listed is the measured time period, the number of interviews in shade and sun, the average meteorological conditions - air temperature (Ta) and physiological equivalent temperature (PET) in the shade and in the sun, relative humidity $(\mathrm{RH})$ and wind speed $(u)$. *Measurements done at Oosterdok are not used in this paper

\begin{tabular}{|c|c|c|c|c|c|c|c|c|c|c|c|c|c|c|c|}
\hline \multirow{2}{*}{$\begin{array}{l}\text { Date and } \\
T_{a, \max }\left({ }^{\circ} \mathrm{C}\right)\end{array}$} & \multirow{2}{*}{\multicolumn{2}{|c|}{$\begin{array}{l}\text { Name of the location and } \\
\text { indication on the map (Fig. 1) }\end{array}$}} & \multicolumn{2}{|c|}{ Situation } & \multirow[t]{3}{*}{ Short description of the location } & \multirow[t]{2}{*}{ Local Climate Zone } & \multirow{2}{*}{$\begin{array}{l}\text { Measured } \\
\text { time period }\end{array}$} & \multicolumn{2}{|c|}{ No. of surveys } & \multicolumn{2}{|l|}{$\mathrm{T}_{\mathrm{a}}\left({ }^{\circ} \mathrm{C}\right)$} & \multicolumn{2}{|c|}{$\operatorname{PET}\left({ }^{\circ} \mathrm{C}\right)$} & \multirow{2}{*}{$\begin{array}{l}\mathrm{RH} \\
(\%) \\
\end{array}$} & \multirow{2}{*}{$\begin{array}{l}\mathrm{u} \\
(\mathrm{m} / \mathrm{s})\end{array}$} \\
\hline & & & shade & sun & & & & shade & sun & shade & sun & shade & sun & & \\
\hline \multirow{2}{*}{$\begin{array}{l}5, \max 161 \\
5-6-2015 \\
31.0\end{array}$} & Dam & $\mathrm{c}$ & & & & 2: Compact mid-rise & & & 45 & & 29.6 & & 47.3 & & \\
\hline & Dam & c & & & Square & 2: Compact mid-rise & 12:00-15:27 & 8 & & 28.6 & & 30.2 & & 44 & 0.8 \\
\hline \multirow{2}{*}{$\begin{array}{l}25-6-2015 \\
22.8\end{array}$} & Stationsplein & L & & & Square & 2: Compact mid-rise & $14: 00-16: 36$ & & 30 & & 23.0 & & 41.5 & 47 & 1.3 \\
\hline & IJ promenade & Q & & & $\begin{array}{l}\text { Promenade along river IJ; river width = } \\
300 \mathrm{~m}\end{array}$ & G: Water & $14: 25-16: 19$ & & 23 & & 22.5 & & 40.4 & 50 & 1.8 \\
\hline \multirow[t]{2}{*}{$\begin{array}{l}30-6-2015 \\
26.4\end{array}$} & Leidseplein & $E$ & & & $\begin{array}{l}\text { Square, with some trees: Huntington elm, } \\
\text { London plane }\end{array}$ & 2: Compact mid-rise & 11:19-16:21 & 26 & 35 & 24.3 & 25.2 & 25.6 & 51.7 & 47 & 0.9 \\
\hline & Vondelpark & 0 & & & $\begin{array}{l}\text { Park with grass and trees: Maple, Ash, } \\
\text { Poplar, Oak }\end{array}$ & B: Scattered trees & $11: 16-16: 20$ & 12 & 35 & 23.3 & 24.0 & 23.9 & 42.8 & 51 & 1.0 \\
\hline \multirow{2}{*}{$\begin{array}{l}1-7-2015 \\
33.0\end{array}$} & Mahlerplein & $\mathrm{F}$ & & & Square & 1: Compact high-rise & $11: 33-15: 45$ & 23 & 38 & 31.7 & 30.6 & 32.2 & 54.1 & 33 & 1.8 \\
\hline & Museumplein & $\mathrm{N}$ & & & Park with grass and a few trees: Linden & 5: Open mid-rise & 11:20-16:15 & 32 & 51 & 30.3 & 30.9 & 33.9 & 49.9 & 37 & 1.3 \\
\hline \multirow{2}{*}{$\begin{array}{l}2-7-2015 \\
30.2\end{array}$} & Dam & c & & & Square & 2: Compact mid-rise & $11: 04-16: 24$ & 30 & 45 & 30.0 & 29.6 & 32.2 & 44.6 & 51 & 0.4 \\
\hline & Magere Brug & $R$ & & & $\begin{array}{l}\text { Narrow bridge crossing river Amstel; river } \\
\text { width }=84 \mathrm{~m}\end{array}$ & 5: Open mid-rise & $11: 05-16: 11$ & & 89 & & 28.7 & & 41.5 & 54 & 1.8 \\
\hline \multirow[t]{2}{*}{$\begin{array}{l}3-7-2015 \\
28.9\end{array}$} & $\begin{array}{l}\text { Oosterdokskade/ } \\
\text { AMG Schmidtstraat }\end{array}$ & I/ & & & $\begin{array}{l}\text { Square in front of tall building/ } \\
\text { Alley between tall buildings }\end{array}$ & $\begin{array}{l}\text { 2: Compact mid-rise } \\
\text { 2: Compact mid-rise }\end{array}$ & 11:09-16:31 & 26 & 66 & 26.2 & 27.5 & 26.8 & 47.7 & 59 & 1.2 \\
\hline & Oosterdok-roof* & $\mathrm{H}$ & & & On the roof top of a museum & 2: Compact mid-rise & 11:09-16:31 & & 90 & & 27.3 & & 46.8 & 58 & 1.0 \\
\hline \multirow{2}{*}{$\begin{array}{l}6-7-2015 \\
21.9\end{array}$} & Spui & $\mathrm{k}$ & & & Street with trees & 2: Compact mid-rise & 11:19-16:17 & 44 & 92 & 20.6 & 21.1 & 19.8 & 35.9 & 56 & 1.1 \\
\hline & $\begin{array}{l}\text { Rembrandtplein/ } \\
\text { Thorbeckeplein }\end{array}$ & $\mathrm{J} /$ & & & $\begin{array}{l}\text { Square/ } \\
\text { Square with trees: London Plane }\end{array}$ & $\begin{array}{l}\text { 2: Compact mid-rise/ } \\
\text { 2: Compact mid-rise }\end{array}$ & $11: 26-16: 17$ & 43 & 84 & 20.8 & 21.2 & 22.0 & 33.4 & 56 & 0.9 \\
\hline \multirow{2}{*}{$\begin{array}{l}19-7-2016 \\
28.9\end{array}$} & Amstelplein & B & & & Square & 5: Open mid-rise & $10: 34-16: 26$ & & 98 & & 26.9 & & 45.4 & 50 & 1.7 \\
\hline & Weesperzijde & U & & & $\begin{array}{l}\text { Quay along river Amstel; } \\
\text { river width }=150 \mathrm{~m}\end{array}$ & 5: Open mid-rise & $10: 57-16: 24$ & & 91 & & 27.1 & & 46.4 & 50 & 0.8 \\
\hline \multirow{2}{*}{$\begin{array}{l}20-7-2016 \\
33.0\end{array}$} & Rembrandtplein & $\mathrm{J}$ & & & Square & 2: Compact mid-rise & $10: 40-16: 25$ & & 80 & & 32.2 & & 48.0 & 39 & 1.6 \\
\hline & Reguliersgracht & $\mathrm{T}$ & & & Bridge over canal; canal width $=26 \mathrm{~m}$ & 5: Open mid-rise & $10: 46-16: 26$ & & 62 & & 31.9 & & 48.9 & 40 & 1.1 \\
\hline \multirow{2}{*}{$\begin{array}{l}24-8-2016 \\
30.4\end{array}$} & Museumstraat & G & & & Pedestrian and bicycle street & 5: Open mid-rise & $11: 31-16: 33$ & & 62 & & 29.3 & & 45.3 & 50 & 0.8 \\
\hline & Museumplein pond & $\mathrm{s}$ & & & Pond in park; dimensions: $85 \times 18 \mathrm{~m}$ & 5: Open mid-rise & $11: 12-16: 35$ & & 113 & & 28.5 & & 46.2 & 52 & 1.4 \\
\hline \multirow{2}{*}{$\begin{array}{l}25-8-2016 \\
30.9\end{array}$} & Stationsplein & L & & & Square & 2: Compact mid-rise & $10: 45-16: 55$ & & 133 & & 30.3 & & 43.5 & 49 & 1.5 \\
\hline & IJ promenade & Q & & & $\begin{array}{l}\text { Promenade along river IJ; river width = } \\
300 \mathrm{~m}\end{array}$ & G: Water & $10: 58-16: 36$ & & 131 & & 29.6 & & 48.8 & 50 & 2.3 \\
\hline \multirow{2}{*}{$\begin{array}{l}26-8-2016 \\
24.2\end{array}$} & Frederiksplein & $P$ & & & Square with trees: Common wingnut & 5: Open mid-rise & $10: 49-16: 30$ & 85 & & 23.4 & & 24.2 & & 67 & 0.3 \\
\hline & Frederiksplein pond & $P$ & & & $\begin{array}{l}\text { Pond with fountain on square with trees: } \\
\text { Common wingnut; pond diameter }=16 \mathrm{~m}\end{array}$ & 5: Open mid-rise & $10: 49-16: 30$ & 105 & & 22.9 & & 23.3 & & 68 & 0.9 \\
\hline
\end{tabular}


location E) and Vondelpark (green location O) on 30-6-2015 (Table 1), we could estimate the thermal effect of a green urban space (Vondelpark) with respect to an impervious urban location (Leidseplein) for sunny as well as shaded conditions. In addition, we could assess the shading effect of trees for a green space (i.e. Vondelpark), and the shading effect of trees for an impervious urban space (i.e. Leideplein). However, moving a weather station each hour between two locations also turned out to complicate the analyses considerably. Therefore, in the second season (2016), we measured with each mobile weather station at only one location throughout the day.

\section{Measurement days and meteorological conditions}

The dates in Table 1 show that measurements were carried out on 12 different days in the summer months (June, July and August) of 2015 and 2016. All days were weekdays. The measurements were taken during the hottest part of the day, starting from around noon until late afternoon. In 2015, four measurement days were part of a heat wave period in the Netherlands lasting from 30th of June to 5th of July 2015. A heatwave period in the Netherlands is defined by the Netherlands Royal Meteorological Institute as a period of five consecutive days with a maximum temperature above $25^{\circ} \mathrm{C}$ including at least three on which the maximum temperature exceeds $30^{\circ} \mathrm{C}$. Days for which air temperatures above $25{ }^{\circ} \mathrm{C}$ and clear skies were forecasted, were chosen to carry out the measurements and the surveys. For this reason, most air temperatures measured at the urban sites reached maximum temperatures well above $25{ }^{\circ} \mathrm{C}$. However, on some days, air temperatures remained lower than forecasted (e.g. 26 August 2016), but PET values always exceeded $33^{\circ} \mathrm{C}$ in the sun, indicating a situation of at least moderate heat stress (Matzarakis and Mayer 1996). Table 1 also lists the maximum air temperature measured at Schiphol airport, a rural reference station of the Netherlands Royal Meteorological Institute $10 \mathrm{~km}$ from the centre of Amsterdam. Also at this site, air temperatures did not always exceed $25^{\circ} \mathrm{C}$.

The meteorological measurements listed in Table 1 indicate that the average humidity on the measurement days was low, between 33 and $68 \%$, and wind speeds measured were calm up to light breeze. These values reflect a typical situation for an urban environment on a hot summer day.

\section{Micrometeorological measurements and assessment of PET}

To measure the meteorological conditions and estimate the PET, we equipped two-wheel hand carts with a Davis Vantage Pro2 weather station (see Fig. 2). This instrument includes sensors that measure air temperature, air humidity,

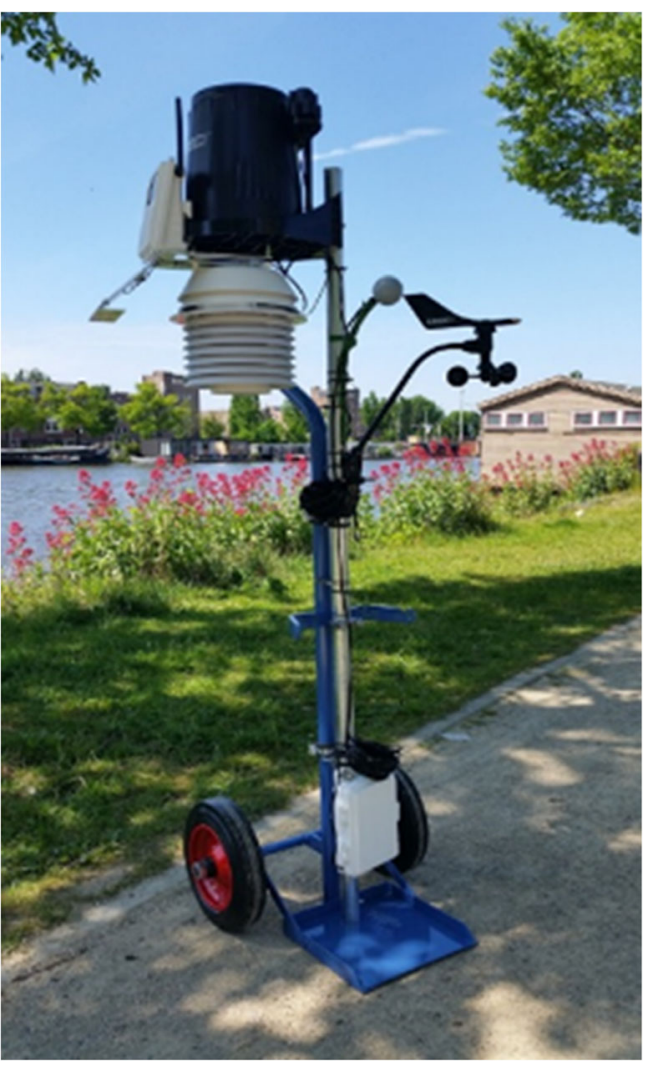

Fig. 2 Mobile weather station. Davis Vantage Pro2 instrument installed on a wheel hand cart

wind speed, wind direction, and global radiation and uses a fan-aspirated radiation shield. The accuracy of the sensors are $0.5{ }^{\circ} \mathrm{C}$ for air temperature, $3 \%$ for air humidity, $5 \%$ for wind speed, $3^{\circ}$ for wind direction and $5 \%$ for global radiation. The globe temperature was measured using an additional $38-\mathrm{mm}$ flat grey globe thermometer, made of a grey painted table tennis ball using a flat grey paint (RAL 7001) following Thorsson et al. (2007). A temperature probe of Davis (type 6372) was used inside the table tennis ball. The accuracy of this sensor is $0.5^{\circ} \mathrm{C}$. The time interval of the recorded meteorological variables was $1 \mathrm{~min}$. The height at which the sensors were installed is $1.1 \mathrm{~m}$, corresponding to the average height of an adult's centre of gravity (Mayer and Hoeppe 1987).

From the globe temperature, the wind speed and the air temperature, the mean radiant temperature $\left(T_{\mathrm{mrt}}\right.$; Mayer and Hoeppe 1987) could be obtained using the method as suggested by Thorsson et al. (2007):

$T_{\text {mit }}=\left[\left(T_{\mathrm{g}}+273.15\right)^{4}+\frac{1.335 \times 10^{8} u^{6}}{\varepsilon D^{4}} \times\left(T_{\mathrm{g}}-T_{\mathrm{a}}\right)\right]^{1 / 4}-273.15$

where $T_{\mathrm{g}}$ is the globe temperature $\left({ }^{\circ} \mathrm{C}\right), u$ is wind speed $(\mathrm{m} / \mathrm{s})$, $T_{\mathrm{a}}$ is air temperature $\left({ }^{\circ} \mathrm{C}\right), \varepsilon$ is the globe emissivity $(0.95)$ and $D$ is the globe diameter (m). 
$T_{\mathrm{mrt}}$ is the most important variable in assessing the thermal comfort situation and calculating the PET. It sums the human body exposure to all short- and long-wave radiation fluxes (direct, diffuse, reflected and emitted) in a given environment (Johansson et al. 2014). Since the method used to assess $T_{\mathrm{mrt}}$ is very sensitive to variations in wind speed, we used 10-min running averages of the meteorological variables as input for calculating $T_{\mathrm{mrt}}$.

The PET was calculated using Rayman software (Matzarakis et al. 2007). Air temperature, relative humidity, wind speed and $T_{\mathrm{mrt}}$ were used as input and the default settings of Rayman were used: gender - male, age -35 years of age, weight $-75 \mathrm{~kg}$, length $-1.75 \mathrm{~m}$, standing, moderate clothing $(\mathrm{clo}=0.9)$ and doing light work $(80.0 \mathrm{~W})$.

\section{Field surveys}

In order to gain insight into the perception of the thermal environment of the urban spaces, we conducted interviews and surveyed people in the near environment of the weather stations, ensuring that the interviewees were in the same thermal environment as the measurement devices. We questioned people walking or sitting in this area. A structured interview form was prepared for the interviews (Table 2). People were asked to give some personal information related to the individual factors that determine thermal sensation (part 2 of the form) and their opinion on the thermal environment (part 3 of the form). Note that some slight differences exist between the surveys used in 2015 and 2016. We based the questions of the surveys on

Table 2 Overview of the questions in the survey

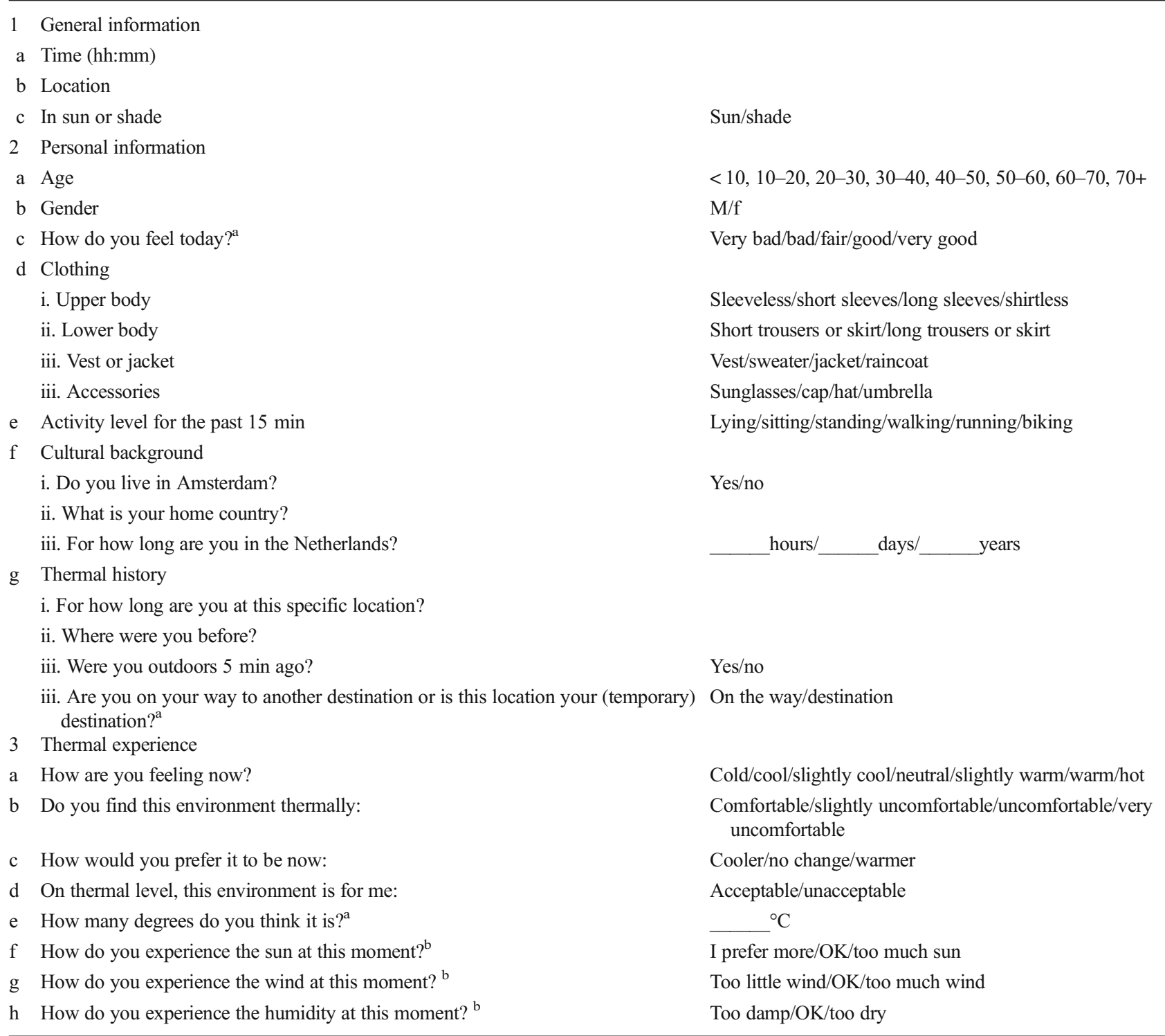

${ }^{a}$ Questions included in the surveys of 2016 only

${ }^{\mathrm{b}}$ Questions included in the surveys of 2015 only 
studies of Johansson et al. (2014), Klemm et al. (2015a), Lenzholzer and Van der Wulp (2010) and Nikolopoulou and Lykoudis (2006). Filling in a questionnaire took 2 to $3 \mathrm{~min}$ and was supported by a researcher.

The total number of surveys that were completed and could be used in this study is 1928. Table 1 lists the number of people that were interviewed at each location. The average gender division of the respondents is $55 \%$ male, $42 \%$ female and of $3 \%$ unknown. The personal characteristics of the respondents with respect to age and origin are presented in Tables 3 and 4. Since most of the measured urban spaces are situated in touristic areas, the number of respondents from countries other than the Netherlands is relatively high (nearly $50 \%)$.

The dataset that we created by doing this questionnaire survey is extensive and can be used to answer a wide range of research questions on thermal experience and its relationship with individual factors such as clothing, age and cultural background. In this study, we especially focused on the answers to the first 4 questions concerning thermal experience (questions 3a, b, c and d). We also checked for some relationships with individual factors. Chi-square tests performed on the dataset of 2015 showed however that experienced thermal comfort (question 3b: Do you find this environment thermally comfortable/slightly uncomfortable/uncomfortable/very uncomfortable) does not have a significant $(p<0.05)$ relationship with any of the individual factors age, gender, clothing, activity level, cultural background or thermal history. In other words, the influence of individual factors on how people experience and value the thermal conditions of the urban spaces was not found in the dataset.

\section{Methodology to assess the thermal effect}

The key results of this study are the thermal effects of green, water and shading in urban spaces. The thermal effects are evaluated in terms of differences in air temperature, PET and thermal experience.

Table 3 Age of the respondents

\begin{tabular}{ll}
\hline Age group & $\%$ \\
\hline $0-9$ & 1 \\
$10-19$ & 18 \\
$20-29$ & 27 \\
$30-39$ & 14 \\
$40-49$ & 13 \\
$50-59$ & 12 \\
$60-69$ & 9 \\
$70+$ & 4 \\
No data & 0 \\
\hline
\end{tabular}

Table 4 Origin of the respondents

\begin{tabular}{ll}
\hline Origin & $\%$ \\
\hline Netherlands & 51 \\
Europe (other than Netherlands) & 30 \\
Africa & 2 \\
Asia & 5 \\
North-America & 6 \\
South-America & 4 \\
Oceania & 1 \\
No data & 1 \\
\hline
\end{tabular}

Table 5 shows which locations (L1 and L2) were compared with each other to estimate the thermal effects. Each time L1 is the expected cooler situation (green, water, shade) and L2 is the reference location. First, the thermal effects of water and urban green (grass and shrubs in parks) were assessed. This was done separately for shaded and sunlit locations. Second, the thermal effects of shading by buildings and shading by trees were assessed. The effect of shading by buildings could be assessed for impervious urban spaces only, while the effect of shading by trees could be assessed for two situations: trees in green (parks) and trees in impervious urban spaces. Note that each time only measurements from the same day were compared.

The thermal effects of water and green urban spaces are always based on measurements and surveys at two locations with two weather stations at the same time. The differences in air temperature and PET listed in Table 5 were therefore calculated as the average of the differences between the two time series (1-min time intervals). A paired sample $t$-test was used to determine whether the mean difference between the two series is significant $(p<0.05)$. The thermal effects of shaded locations are mostly based on measurements from a weather station that was moved each hour between a sunlit and a shaded location. The differences in air temperature and PET listed in Table 5 were therefore calculated as the difference in the average air temperature and PET measured at the two locations. An unpaired sample $t$-test was used to determine whether this difference is significant $(p<0.05)$.

For assessing the differences in thermal experience, we compared interviewed thermal perception, thermal comfort, thermal preference and thermal acceptation between the locations. This corresponds to the four questions of the survey:

3a. Thermal perception-How are you feeling now? cold/cool/slightly cool/neutral/slightly warm/warm/hot

3b. Thermal comfort-Do you find this environment thermally: comfortable/slightly uncomfortable/uncomfortable/very uncomfortable

3c. Thermal preference-How would you prefer it to be now: cooler/no change/warmer

3d. Thermal acceptation-On thermal level, this environment is for me: acceptable/unacceptable 
Table 5 Thermal effects of water, green (grass and shrubs) and shading measured as the difference in air temperature, PET and thermal experience between two locations (L1 and L2). The colours of L1 and L2 indicate the type of location: impervious (grey), grass or shrubs (green) and near urban water (blue). n.s. means that the difference in temperature or thermal comfort is not significant $(p=0.05)$. Bold numbers indicate that the location L2 is cooler-which is counterintuitive. The yellow and dark grey cells for thermal perception, comfort, preference and acceptation indicate a significant difference in thermal experience between L1 and L2. The significance level ( $p$ value) is given. Yellow indicates that $\mathrm{L} 1$ is perceived cooler, more comfortable or acceptable. Grey indicates that L2 is perceived cooler-which is counterintuitive. Concerning preference, yellow indicates that people at L2 prefer a cooler environment than at L1. The thermal effects are numbered from 1 to 19 in line with Fig. 3.

\begin{tabular}{|c|c|c|c|c|c|c|c|c|c|c|}
\hline \multirow[t]{2}{*}{ Effect } & \multirow[t]{2}{*}{ Situation } & \multirow[t]{2}{*}{ No } & \multirow[t]{2}{*}{ Location L1 } & \multirow{2}{*}{$\begin{array}{l}\text { Location L2 } \\
\text { (Reference location) }\end{array}$} & \multicolumn{6}{|c|}{ Cooling effect - difference (L2-L1) in } \\
\hline & & & & & $\begin{array}{l}\mathrm{Ta} \\
\left({ }^{\circ} \mathrm{C}\right)\end{array}$ & $\begin{array}{l}\text { PET } \\
\left({ }^{\circ} \mathrm{C}\right)\end{array}$ & 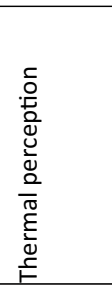 & 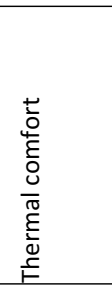 & 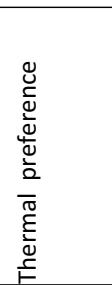 & 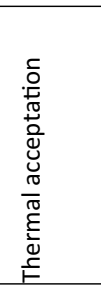 \\
\hline Water & in shade & 1 & Frederiksplein pond & Frederiksplein & 0.5 & 1.0 & $p=0.023$ & n.s. & n.s. & n.s. \\
\hline \multirow{6}{*}{ Water } & \multirow{6}{*}{ in sun } & 2 & Weesperzijde & Amstelplein & -0.2 & -1.0 & n.s. & n.s. & n.s. & n.s. \\
\hline & & 3 & Magere brug & Dam & 1.2 & 4.0 & n.s. & n.s. & n.s. & n.s. \\
\hline & & 4 & Museumplein pond & Museumstraat & 0.7 & -0.5 & n.s. & n.s. & n.s. & n.s. \\
\hline & & 5 & Reguliersgracht & Rembrandtplein & 0.2 & -0.9 & n.s. & n.s. & n.s. & n.s. \\
\hline & & 6 & IJ promenade (2015) & Stationsplein (2015) & 0.5 & 1.0 & n.s. & n.s. & n.s. & n.s. \\
\hline & & 7 & IJ promenade (2016) & Stationsplein (2016) & 0.7 & -5.3 & n.s. & n.s. & n.s. & n.s. \\
\hline Green & in shade & 8 & Vondelpark & Leidseplein & 0.9 & 2.4 & n.s. & n.s. & n.s. & n.s. \\
\hline \multirow{2}{*}{ Green } & \multirow{2}{*}{ in sun } & 9 & Vondelpark & Leidseplein & 1.2 & 1.9 & $p=0.022$ & $p=0.027$ & n.s. & n.s. \\
\hline & & 10 & Museumplein & Mahlerplein & n.s. & 4.2 & n.s. & n.s. & n.s. & n.s. \\
\hline \multirow{5}{*}{$\begin{array}{l}\text { shading } \\
\text { by } \\
\text { buildings }\end{array}$} & \multirow{5}{*}{$\begin{array}{l}\text { in impervious } \\
\text { urban spaces }\end{array}$} & 11 & Dam (5/6) - shade & $\operatorname{Dam}(5 / 6)-$ sun & 1.1 & 17.1 & n.s. & n.s. & n.s. & n.s. \\
\hline & & 12 & Dam (2/7) - shade & $\operatorname{Dam}(2 / 7)-\operatorname{sun}$ & 0.6 & 13.8 & n.s. & n.s. & n.s. & n.s. \\
\hline & & 13 & Mahlerplein - shade & Mahlerplein - sun & n.s. & 21.9 & n.s. & $p=0.036$ & $p=0.018$ & n.s. \\
\hline & & 14 & $\begin{array}{l}\text { AMG Schmidtstraat - } \\
\text { shade }\end{array}$ & Oosterdokskade - sun & 1.3 & 20.9 & $p=0.000$ & $p=0.026$ & $p=0.011$ & $p=0.037$ \\
\hline & & 15 & Spui-shade & Spui - sun & 0.4 & 16.1 & $p=0.005$ & n.s. & n.s. & n.s. \\
\hline \multirow{4}{*}{$\begin{array}{l}\text { shading } \\
\text { by trees }\end{array}$} & \multirow{2}{*}{$\begin{array}{l}\text { in green } \\
\text { urban spaces }\end{array}$} & 16 & Museumplein - shade & Museumplein - sun & 0.6 & 16.0 & n.s. & n.s. & n.s. & n.s. \\
\hline & & 17 & Vondelpark - shade & Vondelpark - sun & 0.7 & 18.8 & $p=0.000$ & n.s. & $p=0.014$ & n.s. \\
\hline & \multirow{2}{*}{$\begin{array}{l}\text { in impervious } \\
\text { urban spaces }\end{array}$} & 18 & Leidseplein - shade & Leidseplein - sun & 0.9 & 16.1 & $p=0.001$ & n.s. & $p=0.025$ & n.s. \\
\hline & & 19 & Thorbeckeplein - shade & Rembrandtplein - sun & 0.5 & 11.5 & n.s. & n.s. & n.s. & n.s. \\
\hline
\end{tabular}

A chi-square test of independence was used to test the difference in perception, comfort, preference and acceptation between two locations. This test is applicable, since we compare two categorical data sets: thermal experience versus the type of urban space. Kendall's Tau-test was applied for thermal acceptation when the sample size of the group 'unacceptable' was too small for applying a chi-square test. Chi-square examines the difference in distribution of two groups and Kendall's tau-test examines the difference in ranking of the two groups.

\section{Results}

Figure 3 and Table 5 show the effects of green (grass and shrubs), water and shading for air temperature, PET and thermal experience. The results clearly demonstrate that the thermal effect of shading is largest. This is especially reflected by large differences in PET of more than $10{ }^{\circ} \mathrm{C}$ between sunlit and shaded locations during the hot summer afternoon. The effect of water and green (grass and shrubs) in urban spaces on the PET ranges up to $4{ }^{\circ} \mathrm{C}$ only. Another clear result depicted in Fig. 3 is that water, green and shading have little impact on the air temperature and reduce the average air temperature by roughly $1{ }^{\circ} \mathrm{C}$, which is close to the measurement accuracy of the sensor $\left( \pm 0.7^{\circ} \mathrm{C}\right)$. The surveys (Table 5$)$ especially indicate significant effects of shading on thermal perception and thermal comfort, but generally no significant effects for water and green.

In more detail, the measurements presented in Fig. 3 indicate that the cooling effect of water with respect to air temperature is very small (less than $1^{\circ} \mathrm{C}$ ). For one situation (no. 2, i.e. 
Fig. 3 The measured thermal effect (expressed as cooling effect) of water, green (grass and shrubs) and shading by buildings and trees on the air temperature (dark grey) and PET (light grey). The numbers on the $\mathrm{x}$-axis link to the numbers of the thermal effects reported in Table 5

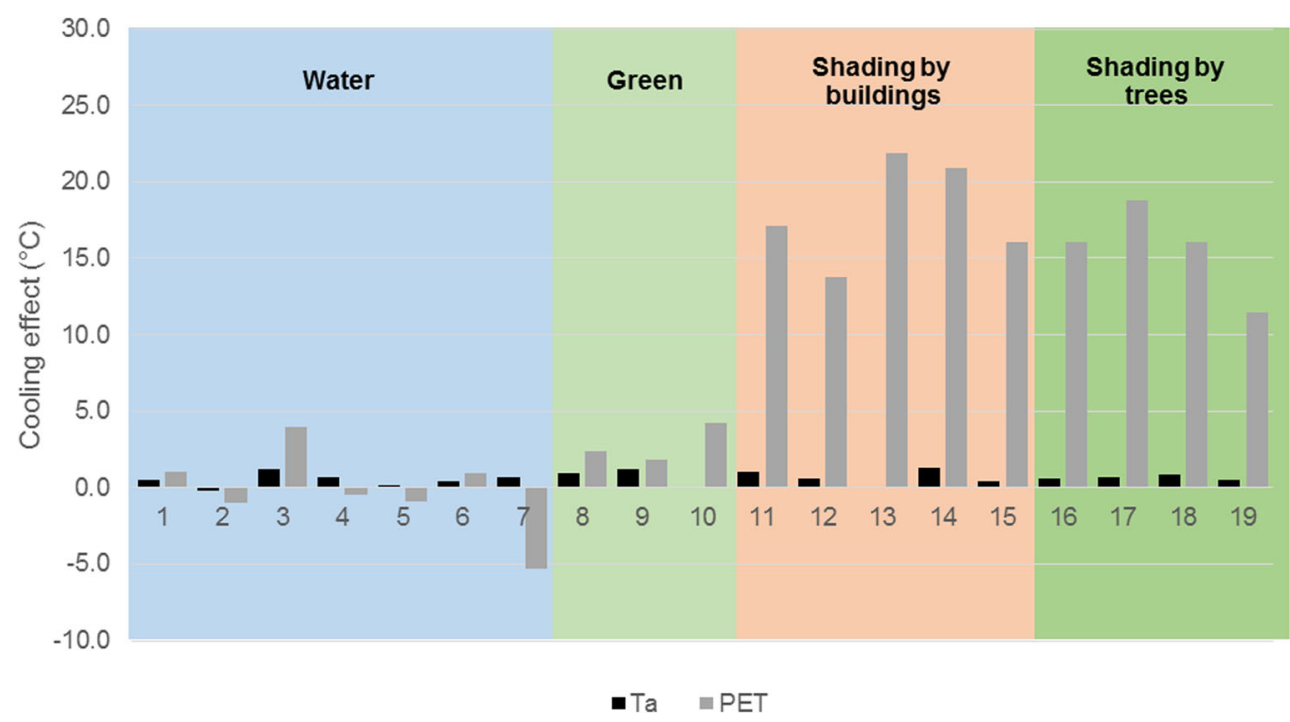

the effect of Amstel river), the thermal effect is even slightly negative, meaning that the air temperature near Amstel river was higher than at the reference location. This might be caused by the high buildings causing more fresh airflow at the reference location (L2). These small temperature differences, however, can also be explained by the sensor accuracy.

PET values generally show a small cooling effect of urban water bodies, ranging up to $4{ }^{\circ} \mathrm{C}$ for the Amstel river (effect no. 3), while for four situations higher PET values were measured near the water bodies. The reason for higher PET values near urban water bodies is different for each location and can often be explained by a higher humidity, less wind or a higher $T_{\text {mrt }}$ at the urban space near the water body with respect to the reference location L2. For instance, the wind speed on 25 August 2016 at the IJ promenade was much larger than at the reference location (Table 1), a difference of $40 \%$. By using the relationship expressed by Eq. 1, this resulted in a higher estimate of $T_{\mathrm{mrt}}$ and a higher PET at the water body than at the reference location. This explains the outlier in Table 5 and Fig. 3 (no. 7).

The small thermal effect of water bodies is also reflected by the surveys. Thermal perception, comfort, preference and acceptation were not significantly different at the locations near water bodies. At one location (fountain on Frederiksplein; no. 1 in Table 5), the respondents perceived the environment near the fountain even warmer than some meters away from it (dark grey cell in Table 5). This we cannot explain from the measurements. It might be related to the fact that Frederiksplein was the only situation where the thermal effect of water was measured for shaded conditions. Also air temperatures were relatively low for this day, about $23{ }^{\circ} \mathrm{C}$ (Table 1). Both conditions do not favour thermal differences between urban spaces.

Also the cooling effect of green urban spaces (grass and shrubs) was found to be small in the measurements, ranging up to $1{ }^{\circ} \mathrm{C}$ in air temperature and $4{ }^{\circ} \mathrm{C}$ in PET. In addition, there is no clear difference in the thermal effect of grass and shrubs between measurements carried out in shade or sun (nos. 8 and 9 in Table 5 and Fig. 3). Neither did people perceive the thermal situation of the green urban space different from the impervious urban spaces, except for one situation, i.e. Vondelpark (no. 9 in Table 5 and Fig. 3). For this situation, urban green (Vondelpark) was rated significantly more comfortable than the impervious urban space Leidseplein, while at the same time the respondents perceived Vondelpark significantly warmer than Leidseplein. These results demonstrate that urban spaces that are perceived as more comfortable (Vondelpark), are not necessarily the same as the locations that are perceived as cooler, even on hot days.

The measurements particularly show that shading by buildings or trees has the largest cooling effect on the urban environment, without clear difference in shading by buildings or trees. This is reflected by large differences in PET shown in Table 5 and Fig. 3. The cooling effect of shading ranges between 12 and $22{ }^{\circ} \mathrm{C}$ in PET, depending on the situation. The measured cooling effect of shading in terms of air temperature is small and ranges up to $1{ }^{\circ} \mathrm{C}$. The surveys indicate that at 4 out of 9 sets of locations, shaded spaces were rated as cooler and at two sets, shaded locations were evaluated as more comfortable than sunlit locations. Also, thermal preference was significantly different between four sets of sunlit and shaded locations, which means that less people preferred a cooler space when they were in the shade.

We also grouped the survey results into four datasets (i.e. water, green, shading by buildings, shading by trees, following Table 5) and investigated the effect in thermal experience for each of these groups. These findings first of all demonstrate that the respondents usually rated the thermal situation of the urban spaces as slightly warm to hot (Fig. 4a). Still, most urban spaces are regarded as thermally comfortable (Fig. 4b), which again implies that slightly warm 


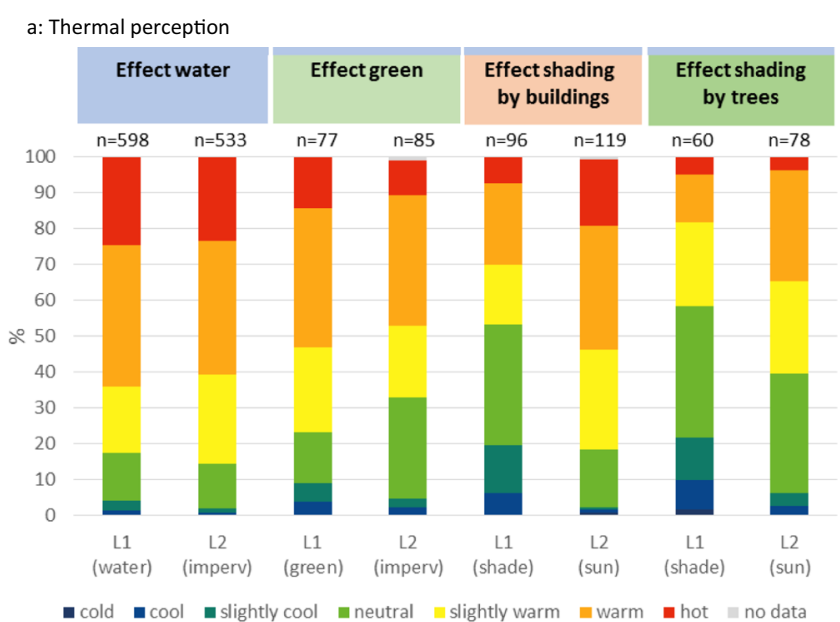

b: Thermal comfort

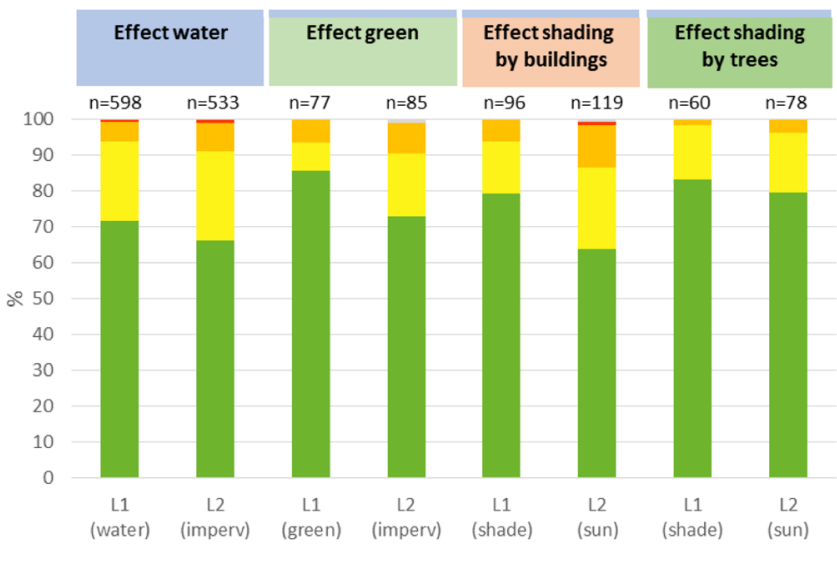

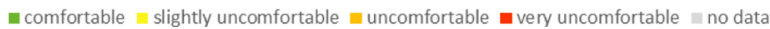

Fig. 4 Survey results showing the effect of water, green, shading by buildings and shading by trees on thermal perception (a), thermal comfort (b), thermal preference (c) and thermal acceptation (d). The thermal effects are indicated by presenting the respondent rates when data are grouped for L1 and L2 locations according to Table 5 (water:

to hot is not directly linked to uncomfortable. There is a preference at all locations towards cooler urban spaces instead of warmer spaces, but most people prefer no change (Fig. 4c). Almost all respondents assess the investigated urban spaces as thermally acceptable (Fig. 4d).

The results in Fig. 4 also indicate that the distribution in thermal experience found at the types of urban spaces that are expected to be cooler (water, green or shading) does not differ much from the reference situation (impervious or sunlit): The surveyed thermal experience of urban spaces close to water bodies is not significantly different from the results at impervious urban spaces. Likewise, the thermal experience of green urban spaces (grass and shrubs) is not different from the impervious sites. Shading by buildings and trees causes the largest effects in thermal experience: Shaded spaces are more often rated as cold, cool or neutral, and more comfortable than sunlit spaces. However, only locations shaded by buildings
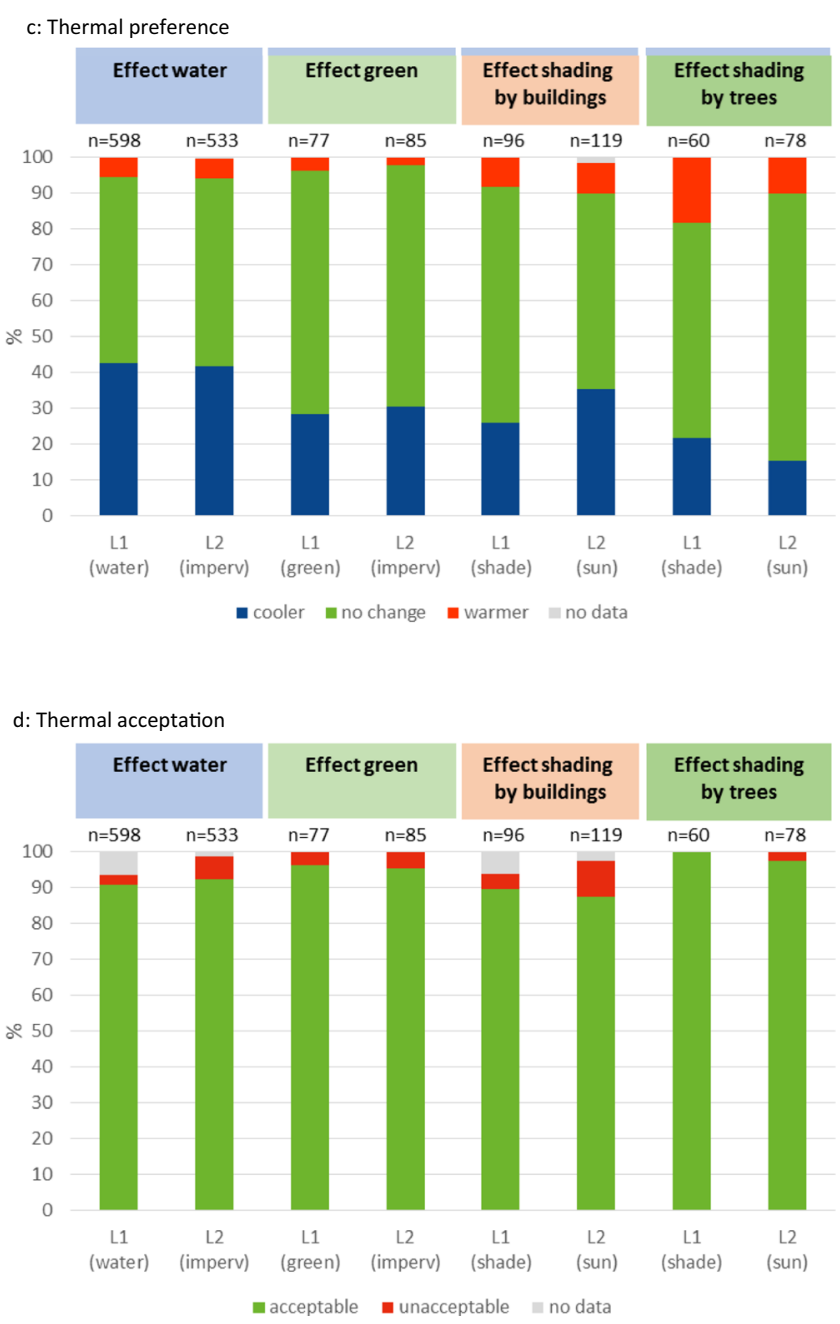

nos. 1-7, green: nos. $8-10$, shading by buildings: nos. $11-15$, and shading by trees: nos. 16-19). The effect of shading by buildings on the thermal perception (a) and thermal comfort (b) are statistically significant $(p<0.05)$

create statistically different responses in thermal perception (Fig. $4 \mathrm{a} ; p=0.000$ ) and thermal comfort (Fig. $4 \mathrm{~b} ; p=$ 0.0267). All other effects of water, green and shading on the thermal experience were statistically insignificant.

\section{Discussion}

\section{On the results compared to earlier studies}

The thermal effect of water, green and shading of buildings and trees found in this study are in line with earlier research. The large thermal effect of shading is for instance in agreement with findings of Middel et al. (2016) who investigated the thermal effect of shaded spaces by trees and artificial shading canopies (photovoltaic canopies) by using meteorological observations and field surveys in a hot desert city in 
Arizona. They concluded that shade plays an important role in designing pedestrian-friendly spaces in cities and that artificial and natural shades are equally efficient. Our results also indicate that shading has a major impact in improving the thermal comfort, in which trees (natural shades) are equally efficient as buildings (artificial shade), especially in terms of PET. This is also in line with Chan et al. (2017), who found a positive correlation between people's thermal comfort and the perceived amount of trees and shade provision in urban parks in Tokyo. They conclude that thermal comfort in parks on summer days could be improved by placing more trees and shade provisions.

The cooling potential of trees was also demonstrated by Klemm et al. (2015a) who measured a substantial improvement of the physical thermal conditions in the Netherlands through the shading effect of street greenery (trees). These meteorological measurements indicated that streets with trees reduce $T_{\text {mrt }}$ by up to $5{ }^{\circ} \mathrm{C}$. The results of Klemm et al. (2015a) also revealed that trees have little influence on the air temperature. This is consistent with our results demonstrating a small thermal effect of trees on air temperature (about $1{ }^{\circ} \mathrm{C}$ cooling) and a considerable effect on PET (ranging up to $19^{\circ} \mathrm{C}$ cooling). Large reductions in PET up to $16^{\circ} \mathrm{C}$ were also found by de Abreu-Harbich et al. (2015) for several tree species in a tropical climate. Their effect depends on the size and the shape of the tree crown, the shape of the leaves, the trunk, the permeability of the crown and the clustering of trees. This was also confirmed by Kong et al. (2017) who investigated how various trees impact thermal comfort in Tokyo. They therefore suggest to plant appropriate vegetation (with respect to tree species and tree formation) for effective tree shading and improvement of the thermal conditions. We however did not differentiate between tree species and clustering in our analysis, since at most urban spaces with trees, urban trees were large and plenty. Moreover, such study would require another measurement set-up and more accurate measurement equipment that can measure smaller temperature differences.

Mobile meteorological measurements carried out with cargo bikes in Rotterdam, the Netherlands, during hot summer days (Heusinkveld et al. 2014; Heusinkveld et al. 2011) also illustrated the large effect of shading on the PET. They measured differences in PET due to effects of shading exceeding $15{ }^{\circ} \mathrm{C}$. They therefore recommend to take shading into consideration in the layout of streets.

In addition, the study of Heusinkveld et al. (2011) demonstrated that the cooling effect of urban water is ambiguous and in the order of $1{ }^{\circ} \mathrm{C}$ in air temperature during daytime, which is similar to our findings. Model simulations of Theeuwes et al. (2013) revealed a similar decrease of only $1{ }^{\circ} \mathrm{C}$ in air temperature and $0.5^{\circ} \mathrm{C}$ in WBGT (wet bulb globe temperature) close to an urban lake, which supports our conclusion that the cooling effect of small water bodies in cities is likely to be small. Saaroni and Ziv (2003) demonstrated that the thermal effect of urban water bodies also depends on wind speed and direction, apart from the size of the water body. Generally, the cooling effect at the downwind side of the pond is larger than at the upwind side. Since all our measurements were carried out at the downwind side of the water bodies, we could not differentiate and investigate the upwind or downwind cooling effect in detail. Neither, we could investigate the differences in the thermal effect between the several types and sizes of water bodies (e.g. urban ponds, rivers and lakes), since each water body was measured on a different summer day. Such study would again require another measurement set-up and more accurate instruments.

\section{On the methodology: the field survey}

Whereas the meteorological measurements in this study generally indicate a statistically significant thermal effect of urban green, water and shading in air temperature and PET, the results of the survey questionnaires did not show much difference in the thermal experience between the urban spaces. The results of the field surveys seem therefore somehow inconsistent to the meteorological observations, which can be explained in several ways. First of all, urban spaces which are measured as cooler do not necessarily need to be perceived as cooler. Second, the contradictions between the measured and experienced thermal effects can be due to inaccuracies in the measurements or limitations of the methodology. In our case, the characteristics of the group of respondents might have influenced towards more positive and thermally comfortable outcomes, because:

- The group of respondents might have been biased by too many tourists, since the measurements were often carried out at touristic spots. This might have resulted in a more positive reaction towards the warm thermal situation of the urban spaces, since most of the tourists are likely to be happy and feeling comfortable on holidays. This, however, was not reflected in the results as people from outside the Netherlands (if we can regard this group as the tourists) did not evaluate the thermal comfort situation of the urban spaces different from people living in the Netherlands. Moreover, a statistical analysis indicated that the country of origin did not have a significant relationship with thermal comfort $(p=0.88)$ in our dataset; a linkage that was for instance found by Kenawy and Elkadi (2013). On the other hand, it might also be justified to evaluate the thermal situation of touristic spots by tourists since they are the actual users of these areas.

- In addition, the group of respondents might have been biased by people that enjoy the thermal situation of the hot summer day. The hot weather situation might have forced people that do not like the high temperatures to stay in other (cooler) urban areas than the ones that were measured. Vulnerable people might even have stayed at home. 
As a consequence, people that would have rated the selected urban spaces as uncomfortable and unacceptable might be missing from the group of respondents, because they chose to stay in other places. This hypothesis is supported by Rutty and Scott (2015), who studied visitors' thermal comfort in the Caribbean beaches. They found that beach users' thermal preference in UTCI (Universal Thermal Climate Index) is up to $18{ }^{\circ} \mathrm{C}$ warmer than the preferred thermal condition identified in existing outdoor bioclimatic studies from urban park settings. This bias can be regarded as a shortcoming of the research methodology and would for instance be an argument for using thermal walks (e.g. Lenzholzer et al. 2016), in which a selected group of respondents assesses the thermal situation of several urban spaces. At the same time, it might not be necessary to include all types of citizens, but only those that make use of the selected urban spaces during a hot day and who were actually part of the survey.

\section{On the comparison between measurements and surveys}

As indicated in the previous section, the micrometeorological measurements and surveys show some remarkable differences. In contrast to the measurements, the questionnaire surveys showed no statistically significant thermal effects of urban green (grass and shrubs) and urban water. According to the surveys, only the thermal effect of shading by buildings was statistically significant in terms of being cooler and more comfortable. Similarly, Klemm et al. (2015a) found a statistically significant thermal effect of street greenery on air temperature and $T_{\mathrm{mrt}}$, but did not find a statistically significant relationship between perceived thermal comfort and the amount of street greenery.

In the introduction of this paper, we also raised the questions: Do meteorological measurements and questionnaire surveys provide the same insight and do surveys add relevant information to the measurements in advising urban professionals and planners? We noticed that meteorological measurements especially give information about the size of the thermal effect, leading to numbers and measurable quantities. This can be of support for urban professionals to decide on the size of interventions and the target value for a thermally comfortable urban design. In the near future, this will become more important in the Netherlands as municipalities might need to demonstrate that their urban areas are heat resilient or well enough adapted to heat. To monitor or assess the thermal situation or the effectiveness of specific heat adaptation measures in an urban space, measurements seem to be a more appropriate approach than using interview surveys.

On the other hand, results from interview surveys provide essential insights in the thermal perception of urban spaces, since it is important that urban spaces which are designed to be cool and comfortable are also valued and perceived by people as cool and comfortable. This information can also be meaningful in convincing urban planners to choose for a certain design. Additionally, interview surveys can provide valuable information on the psychological factors that play a role in the thermal perception, such as mood (question $2 \mathrm{c}$ in Table 2), the time of exposure (question $2 \mathrm{~g}$ in Table 2), expectations or naturalness (Chan et al. 2017; Nikolopoulou and Steemers 2003). These psychological factors were not investigated in this study, but are still valuable when designing thermally comfortable urban spaces. Both thermal perception and the psychological aspects of urban designs can only be investigated by qualitative methods such as observing people's behavior or conducting interview surveys (Lenzholzer et al. 2016) and cannot be retrieved from meteorological measurements.

\section{On the implications for urban professionals}

The major aim of this study was to answer the question of urban professionals which urban spaces provide substantial cooling and are most comfortable during warm days. We aimed to answer this question by using meteorological observations and field surveys. Based on these results, we strongly advise urban professionals to consider shading in designing thermally comfortable urban spaces by using either artificial or natural shades. The shading of trees might be favourable above artificial shading elements because of the many cobenefits of urban trees (Mullaney et al. 2015), including positive effects on mental and physical health, biodiversity and real estate values. Looking at the year round situation in the Netherlands, deciduous trees, which are leafless in winter, are preferable when radiation of the sun is most welcome. When designing outdoor shade, it is also important to consider location, orientation, time and day (Lin et al. 2010) to provide thermally comfortable conditions throughout the entire year and for all users. To allow users to choose their preferred thermal comfort level, Lin et al. (2010) also recommend to use multiple shading types and different shading levels.

We concluded that the cooling potential of small water bodies in cities is negligible and therefore not a good adaptation measure to create cool urban spaces. In discussions with urban professionals from municipalities, we discovered that these conclusions are not easily accepted, since water in urban areas is generally believed to have a cooling effect. Still, other types of urban water might have a more efficient cooling potential, such as water sprays, tangible water, or a combination of water and shading from trees (e.g. Coutts et al. 2013; Nishimura et al. 1998). Urban designers should therefore carefully weigh the use of urban water to improve the pedestrian thermal comfort and might need to consider other forms of water. 
A topic that was not investigated in this study but which is important for urban professionals to adapt cities to heat are the design requirements to be sufficiently adapted to urban heat. Principles to guide climate-responsive design and planning with respect to heat are still lacking (Bowler et al. 2010). In addition, there is little understanding of what people and citizens prefer or need. Sometimes a PET of $>41{ }^{\circ} \mathrm{C}$, indicating extreme heat stress in Western/Central Europe (Matzarakis and Mayer 1996; Cheung and Jim 2017), is used as a threshold value for designing. (NB: Table 1 shows that this PETvalue was exceeded on 18 of the 21 locations measured in the sun.) Investigating the thermal perception, comfort and preferences with field surveys could help in setting these design requirements and making choices which urban spaces are experienced as thermally comfortable.

\section{Conclusions}

- The findings of this research prove that shading urban spaces (by trees or buildings) is the most effective in creating cooler conditions in urban environments during hot summer days. This is confirmed by PET values which are 12 to $22{ }^{\circ} \mathrm{C}$ lower than sunlit spaces. Urban green spaces (grass and shrubs) were also found to be cooler in terms of PET, but their cooling effect is much smaller $\left(2\right.$ to $4{ }^{\circ} \mathrm{C}$ reduction in PET). Also, the thermal effect of small urban water bodies is small and ambiguous, since it sometimes seems to cool and sometimes seems to warm the near urban environment (between $-4{ }^{\circ} \mathrm{C}$ and $5{ }^{\circ} \mathrm{C} \mathrm{PET}$ ).

- The air temperature of urban spaces is not much influenced through shading, urban water or grass. The thermal effect of these types of urban spaces on air temperature is around $1{ }^{\circ} \mathrm{C}$ cooling.

- The results of this study highlight the importance of shading in urban design to reduce heat stress. We therefore strongly advise urban professionals to consider shading in designing thermally comfortable urban spaces.

- Meteorological measurements are especially useful to understand the physical thermal conditions and effects of urban spaces and designs. Since meteorological data provide quantifiable thermal effects, they can be more easily linked and translated to target values or guidelines to reduce urban heat in practice than surveys.

- Surveys provide insights in the thermal perception of an urban design and the psychological factors involved. This type of information is especially interesting to set design requirements for urban spaces to be thermally comfortable.

Acknowledgements This work is part of the research SIA-programme 'Urban climate resilience - Turning climate adaptation into practice' with project number 2014-01-30P, which is (partly) financed by the Netherlands Organisation for Scientific Research (NWO). The aim of this project is to support urban professionals turning localised climate adaptation into practice. The authors would like to thank all the students, scholars and colleagues who helped to conduct the surveys and do the measurements. We would like to thank Andy Bruijns and Lyske de Bildt who contributed to the manuscript by providing figures and data. Jordy Tak and Nanda Piersma are especially mentioned for their statistical analyses on the datasets. We thank Linda Ruddy for providing language help and proof reading the manuscript. The data of this research are available at https://doi.org/10.21943/auas.7359206.

Open Access This article is distributed under the terms of the Creative Commons Attribution 4.0 International License (http:// creativecommons.org/licenses/by/4.0/), which permits unrestricted use, distribution, and reproduction in any medium, provided you give appropriate credit to the original author(s) and the source, provide a link to the Creative Commons license, and indicate if changes were made.

\section{References}

Bowler DE, Buyung-Ali L, Knight TM, Pullin AS (2010) Urban greening to cool towns and cities: a systematic review of the empirical evidence. Landscape Urban Plann 97(3):147-155

CBS (2017) Statline electronic databank

Chan SY, Chau CK, Leung TM (2017) On the study of thermal comfort and perceptions of environmental features in urban parks: a structural equation modeling approach. Build Environ 122:171-183

Cheung PK, Jim CY (2017) Determination and application of outdoor thermal benchmarks. Build Environ 123(Supplement C):333-350

Coutts A, Tapper N, Beringer J, Loughnan M, Demuzere M (2013) Watering our cities: the capacity for water sensitive Urban Design to support urban cooling and improve human thermal comfort in the Australian context. Prog Phys Geogr 37(1):2-28

De Abreu-Harbich LV, Labaki LC, Matzarakis A (2015) Effect of tree planting design and tree species on human thermal comfort in the tropics. Landscape Urban Plann 138:99-109

EEA (2016) Urban adaptation to climate change in Europe 2016. Transforming cities in a changing climate. European environmental agency. EEA report, No 12/2016. https://doi.org/10.2800/021466

Heusinkveld BG, Van Hove B, Jacobs CMJ (2011) Ruimtelijke analyse van het stadsklimaat in Rotterdam. Wageningen UR, Wageningen

Heusinkveld BG, Steeneveld GJ, Van Hove LWA, Jacobs CMJ, Holtslag AAM (2014) Spatial variability of the Rotterdam urban heat island as influenced by urban land use. J Geophys Res Atmos 119(2):677692

IPCC (2014) Impacts, adaptation and vulnerability. Chapter 8. Urban Areas

Johansson E, Thorsson S, Emmanuel R, Krüger E (2014) Instruments and methods in outdoor thermal comfort studies - the need for standardization. Urban Climate 10:346-366

Kenawy I, Elkadi H (2013) The impact of cultural and climatic background on thermal sensation votes. In PLEA 2013: Proceedings of the 29th sustainable architecture for a renewable future conference, Munich Germany, 1-6

Klemm W, Heusinkveld BG, Lenzholzer S, Van Hove B (2015a) Street greenery and its physical and psychological impact on thermal comfort. Landsc Urban Plann 138:87-98

Klemm W, Heusinkveld BG, Lenzholzer S, Jacobs MH, Van Hove B (2015b) Psychological and physical impact of urban green spaces on outdoor thermal comfort during summertime in the Netherlands. Build Environ 83:120-128

Kong L, Lau KK-L, Yuan C, Chen Y, Xu Y, Ren C, Ng E (2017) Regulation of outdoor thermal comfort by trees in Hong Kong. Sustainable Cities and Society 31:12-25 
Lenzholzer S (2010) Engrained experience - a comparison of microclimate perception schemata and microclimate measurements in Dutch urban squares. Int J Biometeorol 54:141-150

Lenzholzer S, Koh J (2010) Immersed in microclimatic space: microclimate experience and perception of spatial configurations in Dutch squares. Landsc Urban Plann 95(1):1-15

Lenzholzer S, Van der Wulp N (2010) Thermal experience and perception in the built environment of Dutch urban squares. J Urban Design 15(3):375-401

Lenzholzer S, Klemm W, Vasilikou C (2016) Qualitative methods to explore thermos-spatial perception in outdoor urban spaces. Urban Climate 23:231-249. https://doi.org/10.1016/j.uclim.2016.10.003

Lin T-P, Matzarakis A, Hwang R-L (2010) Shading effect on long-term outdoor thermal comfort. Build Environ 45(1):213-221

Lindberg F, Thorsson S, Rayner D, Lau K (2016) The impact of urban planning strategies for reducing heat stress in climate change perspective. Sustain Cities Soc 25:1-12

Matzarakis A, Mayer H (1996) Another kind of environmental stress: thermal stress. WHO colloborating centre for Air Quality Management and Air Pollution Control. Newsletter 18:7-10

Matzarakis A, Rutz F, Mayer H (2007) Modelling radiation fluxes in simple and complex environments - application of the RayMan model. Int J Biometeorol 51:323-334. https://doi.org/10.1007/ s00484-006-0061-8

Mayer H, Hoeppe P (1987) Thermal comfort of man in different urban environments. Theor Appl Climatol 38:43-49

Middel A, Selover N, Hagen B, Chhetri N (2016) Impact of shade on outdoor thermal comfort - a seasonal field study in Tempe, Arizona. Int J Biometeorol 60:1849-1861

Molenaar RE, Heusinkveld BG, Steeneveld GJ (2015) Projection of rural and urban human thermal comfort in the Netherlands for 2050. Int J Climatol 36:1708-1723. https://doi.org/10.1002/joc.4453

Mullaney J, Lucke T, Trueman SJ (2015) A review of benefits and challenges in growing street trees in paved urban environments. Landsc Urban Plan 134:157-166

Nikolopoulou M, Steemers K (2003) Thermal comfort and psychological adaptation as a guide for designing urban spaces. Energ Build 35(1): 95-101
Nikolopoulou M, Lykoudis S (2006) Thermal comfort in outdoor urban spaces: analysis across different European countries. Build Environ 41(11):1455-1470

Nishimura N, Nomura T, Iyota H, Kimoto S (1998) Novel water facilities for creation of comfortable urban micrometeorology. Sol Energy 64(4-6):197-207

Rutty M, Scott D (2015) Bioclimatic comfort and the thermal perceptions and preferences of beach tourists. Int J Biometeorol 59(1):37-45

Saaroni H, Ziv B (2003) The impact of a small lake on heat stress in a Mediterranean urban park: the case of Tel Aviv, Israel. Int J Biometeorol 47(3):156-165

Steeneveld GJ, Koopmans S, Heusinkveld BG, Van Hove LWA, Holtslag AAM (2011) Quantifying urban heat island effects and human comfort for cities of variable size and urban morphology in the Netherlands. J Geophys Res Atmos 16:D20129. https://doi.org/10. 1029/2011JD015988

Stewart ID, Oke TR (2012) Local climate zones for urban temperature studies. Bull Am Meteorol Soc 93(12):1879-1900

Taleghani M, Kleerekoper L, Tenpierik M, Van den Dobbelsteen (2015) Outdoor thermal comfort within five different urban forms in the Netherlands. Build Environ 83:65-78

Theeuwes NE, Solcerová A, Steeneveld GJ (2013) Modeling the influence of open water surfaces on the summertime. J Geophys Res Atmos 118:8881-8896. https://doi.org/10.1002/jgrd.50704

Thorsson S, Lindqvist M, Lindqvist S (2004) Thermal bioclimatic conditions and patterns of behaviour in an urban park in Göteborg, Sweden. Int J Biometeorol 48:149-156

Thorsson S, Lindberg F, Eliasson I, Holmer B (2007) Different methods for estimating the mean radiant temperature in an outdoor urban setting. Int J Climatol 27(14):1983-1993. https://doi.org/10.1002/ joc. 1537

Van Hove LWA, Jacobs CMJ, Heusinkveld BG, Elbers JA, van Driel BL, Holtslag AAM (2015) Temporal and spatial variability of urban heat island and thermal comfort within the Rotterdam agglomeration. Build Environ 83:91-103

Yahia M, Johansson E (2013) Evaluating the behaviour of different thermal indices by investigating various outdoor urban environments in the hot dry city of Damascus, Syria. Int J Biometeorol 57:615-630. https://doi.org/10.1007/s00484-012-0589-8 